\title{
Geogebra: uma ferramenta que auxilia no estudo de curvas
}

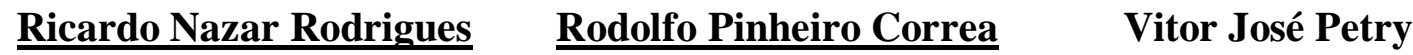 \\ Universidade Tecnológica Federal do Paraná - Licenciatura em Matemática \\ 80230-901, Campus Curitiba, Curitiba, PR \\ E-mail: ricnr.10@hotmail.com, nico16g@gmail.com, vpetry@utfpr.edu.br
}

\begin{abstract}
RESUMO
Ao estudar gráficos de diversos tipos de funções é preciso prestar atenção no comportamento apresentado pelas curvas representativas destas, ao variar alguns de seus parâmetros. Estas variações de parâmetros podem modificar a imagem, a curvatura, o período (no caso de funções periódicas), o domínio de definição, entre outros aspectos. Quando vários desses parâmetros podem ser alterados simultaneamente, frequentemente alunos apresentam dificuldade na compreensão dos padrões que se estabelecem e no que cada parâmetro influência na representação gráfica da função em estudo. Neste aspecto softwares dinâmicos podem facilitar a análise dos gráficos, pois estes programas possibilitam a construção e a manipulação das curvas. De acordo com Rezende [2],
\end{abstract}

Os argumentos favoráveis ao uso desses softwares são bem diversificados. Experimentar, criar estratégias, fazer conjecturas, argumentar e deduzir propriedades matemáticas são, em verdade, ações desejáveis no ensino de matemática em qualquer domínio de conhecimento e nível de ensino. Nesse sentido, essas ferramentas computacionais são bem-vindas no ensino das funções reais. Em particular, o software GeoGebra, com excelente interface dinâmica entre os sistemas algébrico e geométrico de representações. (REZENDE, 2012, pág. 78)

No presente trabalho fizemos construções bidimensionais utilizando o software GeoGebra versão 4.2.56. Para isto apresentamos os gráficos de algumas curvas, avaliando propriedades e seus comportamentos. O GeoGebra é uma ferramenta matemática criada na arquitetura java capaz de combinar conceitos algébricos e geométricos. Desde sua criação, vem se tornando cada vez mais flexível a sua utilização, sendo de fácil adaptação ao uso de docentes e de acadêmicos. É uma das principais formas de combinar geometria com álgebra e segundo Sangwin (2007) [3] o Geogebra é um software dinâmico em que é possível trabalhar com pontos, vetores, segmentos, linhas e com secções cônicas. Além disso, pode-se trabalhar com equações e coodernadas que são inseridas diretamente no programa. Nesse aspecto o software foi escolhido para esta analise das curvas, pois possibilita um maior dinamismo na junção entre os conceitos matemáticos citados, sendo possível inserir controles deslizantes ou campos de entrada para cada coeficiente do objeto de trabalhado. Para a implementação neste software há duas formas de insersão de variáveis: por botões ${ }^{1}$ e por um campo de entrada ${ }^{2}$. Na sequência, apresentamos alguns exemplos de atividades desenvolvidas neste trabalho:

Espiral de Arquimedes: É uma curva descrita pela trajetória de um ponto em que a distância á partir da origem e o ângulo rotacionado são proporcionais.

Se considerarmos o conceito de funções reais de variável real, teremos problemas na sua representação. Assim torna-se necessário representá-la na forma vetorial, a exemplo o que ocorre na representação de uma circunferência. Para fazer a representação vetorial, usa-se equações na forma polar ou paramétricas, para as quais, o GeoGebra conta com um comando de entrada chamado curvas. No caso da espiral de Arquimedes as equações que a geram são dadas por $r=a \theta$, na forma polar, ou por $f(t)=(a * t * \cos (t), a * t * \operatorname{sen}(t))$ em forma paramétrica.

Para construir a curva no GeoGebra basta definir o parâmetro a como entrada ou como comando deslizante. Fazendo isto em entrada com o script Curva[ $\langle$ Expressão $\rangle$, 〈Expressão $\rangle$, $<$ Variável $>$ <Valor Inicial $>$, <Valor Final $>$, podemos definir

\footnotetext{
${ }^{1}$ Localizam-se no canto superior do programa, abaixo do menu.

${ }^{2}$ Campo de entrada localiza-se no canto inferior do programa.
} 
Curva $\left[a^{*} t^{*} \operatorname{sen}(t), a * t * \cos (t), t, 0,2 * p i\right]$. Note que é necessário também atribuir valores inicial e final limitando a variável $t$ da curva, com $t$ inicial valendo zero e $t$ final valendo $2 \pi$, isto é, $t \in[0,2 \pi]$. Além do comando de curva também é possível inserir equações paramétricas diretamente nas coordenadas de um ponto. Para isto insere-se a variável principal, no caso $t$, como controle deslizante, e um ponto qualquer e alteram-se suas coordenadas em propriedades para $(a * t * \operatorname{sen}(t), a * t * \cos (t))$ ou pelo comando de entrada $A=(a * t * \cos (t), a * t * \operatorname{sen}(t))$. Este método de inserção possibilita gerar rastro ${ }^{3}$ e a compreensão da relação entre $t \mathrm{e} o$ ponto que ele gera a partir das coordenadas dadas, mostrado na figura 1.

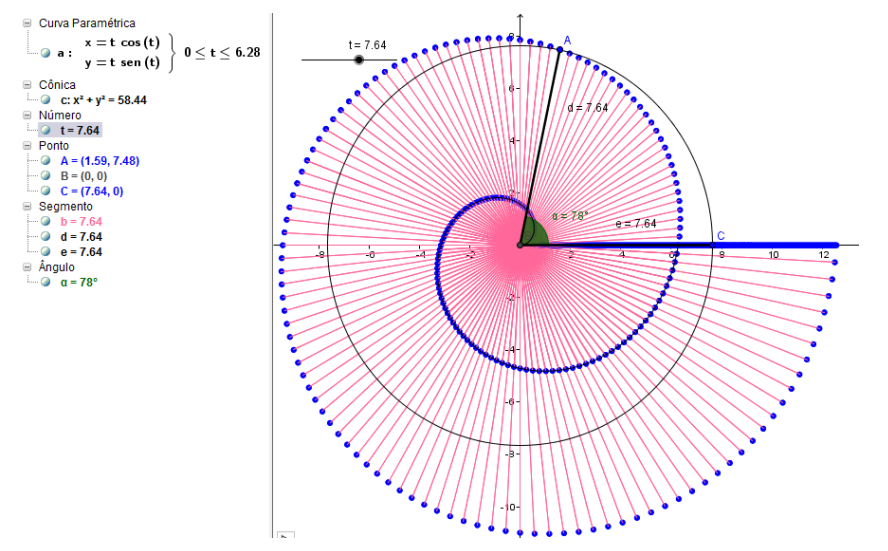

Figura 1: rastro obtido na construção da Espiral de Arquimedes

Cicloide: Chama-se cicloide a curva definida por um ponto de uma circunferência que gira sem deslizar sobre uma reta[1]. A forma paramétrica de inserção da cicloide é dada por $x=a(t-\operatorname{sen}(t))$ e $y=a(1-\cos (t))$ onde $a$ é o raio da circunferência. Essa curva também pode ser criada utilizando sua sua definição. Para isto é necessário criar um parâmetro, relativo ao raio e uma variável referente a posição do círculo na posição horizontal, sendo que o valor máximo da posição do círculo será quando a circunferência realizar uma volta completa.

Criados os controles, raio $(a)$ e comprimento $(l)$, define-se então o centro da circunferência sobre a qual o ponto deve girar com as coordenadas $A=(l, a)$ onde o comprimento $(l)$ será a variável. A próxima etapa será a criação de um ponto auxiliar na posição $B=(l, 0)$ pois a partir dele faremos um ponto $P$ girar em torno da circunferência. O ponto de giro será criado

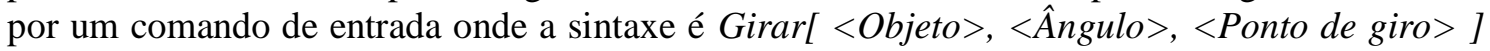
logo o comando fica: $P=\operatorname{Girar}[B, l / a, A]$, feito isso basta exibir o rastro $^{4}$ do ponto que está girando e a cicloide será construída a partir de seu rastro.
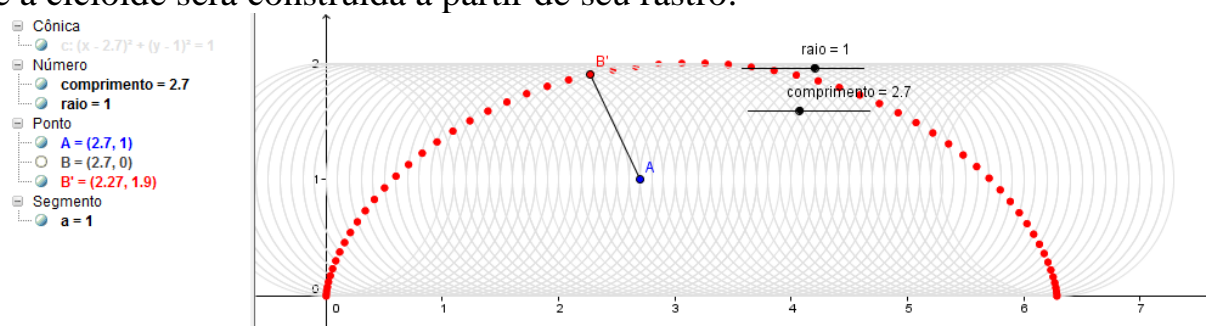

Figura 2: rastro obtido na construção da Ciclóide

É possível criar um circulo dados centro $(A)$ e o raio $(l)$ e em suas propriedades pode-se alterar sua cor. Também é possível nos controles deslizantes diminuir a velocidade e o incremento que possibilitará ao Software criar mais pontos no rastro, conforme figura 2. Lembramos aqui que o rastro é uma sequência de pontos, isto é, embora a curva seja contínua,

\footnotetext{
${ }^{3}$ Em propriedades do ponto: Habilitar rastro.
} 
sua representação será na forma discreta, porém não é objetivo deste trabalho ampliar esta discussão.

Folium de Descartes: Discutido primeiramente por Descartes em 1638, o Folium tem a equação cartesiana $x^{3}+y^{3}=3 a x y$ e paramétrica $x=\frac{3 a t}{1+t^{2}}, y=\frac{3 a t^{2}}{1+t^{3}}$ e apresenta uma assíntota descrita pela equação $x+y+a=0$. Esta curva se relaciona com a Trisectrix de MacLaurin através de uma relação afim.

É possível construir esta curva de forma a dispensar a forma paramétrica no GeoGebra utilizando a entrada curva implícita a qual tem a sintaxe: CurvaImplícita $[\langle f(x, y)\rangle]$. Assim, o Folium com o uso desta função fica CurvaImplícita $\left[x^{3}+y^{3}-3 * a * x * y\right.$ ] onde deve-se inserir previamente o comando deslizante para $a$. O entendimento de tal comando se dá tomando $f(x, y)=k$, onde $k$ é constante. Note que tal comando é uma ferramenta muito útil a fim de entender curvas de nível. Considerando a equação $f(x, y)=x^{3}+y^{3}-3 a x y$ temos que $0=x^{3}+y^{3}-3 a x y-f(x, y)$ e inserimos o parâmetro $k$ que represente $f(x, y)=k$ de forma que a implementação ficará: CurvaImplícita $\left[x^{\wedge} 3+y^{\wedge} 3-3 * a * x * y-k\right]$. Alterando o parâmetro com um incremento fixo é possível compreender com facilidade as curvas de níveis de uma função de duas variáveis reais, conforme mostrado na figura 3 .
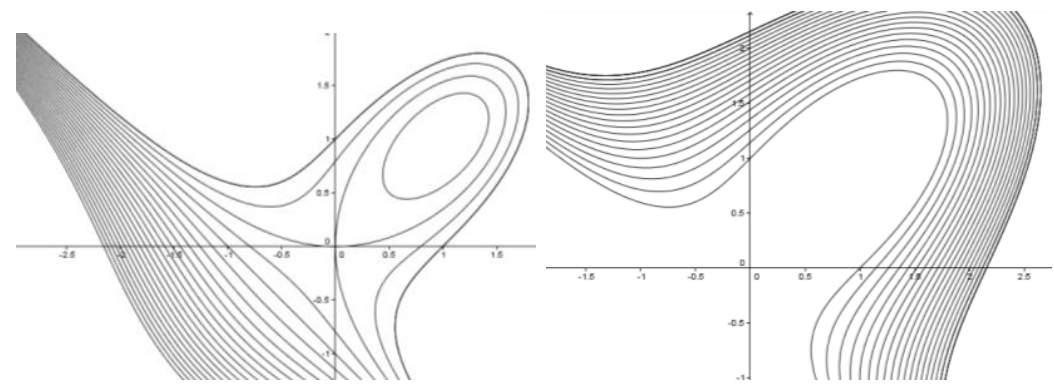

Figura 3: curvas de nível do Folium de Descartes ${ }^{4}$

Finalmente, vale considerar que no presente trabalho foram apresentadas algumas curvas para ilustrar a utilização de diferentes comandos do GeoGebra que facilitam a compreensão do comportamento dessas curvas. Ressaltamos que tais comandos não são únicos ou exclusivos para cada caso, sendo que cabe ao usuário pesquisar e adaptar na sua prática a utilização destes comandos. Muito se fala da compreensão dos conceitos matemáticos e existe varias ferramentas digitais que facilitam o entendimento deste conceito. Mesmo com acesso a um software dinâmico, muitas ferramentas, funcionalidades e utilidades se mantêm ocultas. Deste modo cabe aos professores, pesquisadores e estudantes descobrir e buscar novas formas de utilizar as ferramentas matemáticas que quando descobertas colaboram muito para a criação de modelos e compreensão de conceitos matemáticos, como foi ilustrado neste trabalho.

Palavras-chave: Geogebra, curvas ,funções.

\section{Referências}

[1] Carvalho, Benjamin - Desenho Geométrico. Ed. Ao Livro Técnico, São Paulo; 1988.

[2] Rezende M. W.; Pesco U. D.; Bortolossi J. H.; - Explorando aspectos dinâmicos no ensino de funções reais com recursos do GeoGebra. $1^{\text {a }}$. Conferência Latino Americana de GeoGebra, pp. 77, 2012.

[3] Sangwin C. - A brief review of GeoGebra: dynamic mathematics. MSOR Connections, Vol. 7, pp. 36, 2007.

\footnotetext{
${ }^{4}$ Cada linha representa uma curva de nível ( $\mathrm{k}$ crescente da direita para a esquerda).
} 